\title{
Aspectos éticos da avaliação científica nas áreas médicas e biomédicas
}

\author{
Ethical aspects of scientific evaluation in medical and biomedical areas
}

Guilherme Malafaia

A princípio, não há como esconder a minha satisfação em participar como membro do corpo editorial dos Arquivos Brasileiros de Ciências da Saúde (ABCS), um periódico sério e respeitado que, desde o final da década de 1970, quando ainda era denominado Arquivos Médicos do ABC, vem contribuindo significativamente para a divulgação da ciência brasileira ligada à saúde pública. Atualmente, vivenciamos a ascensão da revista na qualificação do Programa Qualis Periódicos (atualização 2012) da Coordenação de Aperfeiçoamento de Pessoal de Nível Superior (CAPES). A revista já é B3 (nas áreas de Enfermagem e Educação Física)!

Certamente, essa ascensão é reflexo direto do esforço do corpo editorial dos ABCS e do conselho consultivo da revista, que, com presteza e de forma voluntária, também têm contribuído substancialmente para o crescimento da revista e da qualidade dos trabalhos nela publicados. Nesse sentido, um campo merecedor de destaque, e que, há algum tempo vem sendo discutido entre diversos estudiosos e em variados periódicos científicos, refere-se à avaliação por pares em revistas da área da saúde. Quando levamos em consideração a necessidade de publicarmos trabalhos bons e de alto impacto, na tentativa de equipararmos os periódicos brasileiros àqueles reconhecidos internacionalmente, o papel e a contribuição dos revisores nesse processo se tornam ainda maiores.

Sem dúvidas, o processo de avaliação por pares trata-se de um tema importante que tem suscitado discussões no âmbito da publicação de trabalhos acadêmico-científicos. Mantida no esteio do princípio da independência, a avaliação crítica dos artigos a serem publicados é componente indissociável do trabalho acadêmico, no qual se inclui o processo de produção e avaliação científica.

A importância desse tema foi amplamente discutida no Sixth International Congress of Peer Review and Biomedical Publication em Vancouver, no Canadá, realizado em 2009, e promete ser novamente abordado no Seventh International Congress of Peer Review and Biomedical Publication, a ser realizado em setembro de 2013, na cidade de Chicago, Illinois, EUA ${ }^{1}$.

Se considerarmos que com o conceito publish or perish a comunidade científica mundial se viu pressionada a publicar, a qualquer custo, sua produção científica, as questões relacionadas ao julgamento dos manuscritos submetidos para publicação se impõem como importantes salvaguardas que devem ser levadas em consideração, visando a divulgação de trabalhos relevantes e de grande contribuição científica.

Contudo, mesmo reconhecendo a importância do processo de avaliação por pares dos manuscritos biomédicos e a disseminação e aceitação desse processo editorial nos últimos anos, que evidenciam suas grandes vantagens, o sistema de revisão de artigos ainda sofre críticas motivadas, sobretudo, pelas distorções do seu uso.

Nesse contexto, três aspectos merecem destaque; os quais foram discutidos por Pessanha ${ }^{2}$, no final da década de 1990, mas que valem vivamente para os dias atuais. São eles: i) a propensão positiva ou negativa a certos temas por parte dos revisores ou editores pode introduzir distorções adicionais à publicação, devido, principalmente, a conflitos de interesses e enfrentamentos pessoais e/ou interesses comerciais; ii) a avaliação aumenta desnecessariamente o tempo entre a apresentação do manuscrito e sua publicação e iii) a possibilidade de argumentos preconceituosos sobre minorias étnicas, sexuais, ideológicas ou nacionais. Aliado a esses aspectos, não se pode deixar de destacar a importância das questões éticas, intrínsecas à avaliação/julgamento dos artigos científicos submetidos à publicação nos periódicos biomédicos. Conforme descrito por Pessanha ${ }^{2}$, "[...] os casos de fraude, plágio e outros tipos de conduta inadequados no processo de produção e comunicação da ciência repetem-se com frequência crescente nas comunidades científicas”. Inúmeros trabalhos sobre a questão da ética na ciência, conforme demonstrado no estudo de Pizzani et al. ${ }^{3}$, estão sendo publicados nos últimos anos. O Quadro 1, adaptado do conhecido livro de Marcel C. LaFollette, intitulado Stealing into print, dedicado inteiramente a esse problema, apresenta alguns exemplos de má conduta por parte de autores, avaliadores e editores de periódicos biomédicos ${ }^{4}$.

No entanto, parece haver uma grande contradição entre os preceitos éticos preconizados em vários documentos que estabelecem as diretrizes para a elaboração e publicação de manuscritos biomédicos, como é o caso do conhecido Uniform Requirements for Manuscripts Submitted to Biomedical Journals, e o cumprimento dessas diretrizes por parte das várias instâncias relacionadas ao processo editorial (autores, revisores e editores de periódicos). No recente estudo de Tavares-Neto e Azevêdo 5 , no qual os autores se propuseram a avaliar os destaques éticos existentes nas “Instruções aos autores” de periódicos nacionais,

Departamento de Ciências Biológicas do Instituto Federal Goiano - Campus Urutaí; Pesquisador do Núcleo de Pesquisa em Ciências Ambientais e Biológicas (NPCAB) - Urutaí (GO), Brasil.

E-mail: guilhermeifgoiano@gmail.com 
foi possível notar que há grande necessidade da comunidade acadêmica reconhecer as suas responsabilidades com a comunidade em geral, no que se refere à produção e divulgação de boa ciência. Após analisarem 20 periódicos biomédicos brasileiros, os autores observaram, dentre outros aspectos, que uma das instruções aos autores mais frequentes nos periódicos (55\%) foi a que exige a explicação sobre a existência de algum conflito de interesse. No entanto, conforme descrito pelos próprios autores ${ }^{5}$, a surpresa decorre do fato de que nenhum dos periódicos analisados deixa explícito em suas “Instruções aos autores” a preocupação do editor sobre a existência de conflitos de interesses entre os revisores de artigos e os autores. Outra contradição é observada quando nota-se que, dos periódicos analisados, nenhum esclarece sobre a prevenção de fraudes, plágio e ou fabricação de dados. Esses resultados, sem dúvidas, reforçam a necessidade de superação de alguns aspectos ainda observados na atualidade no que diz respeito à produção e divulgação de trabalhos científicos.

Conforme oportunamente destacado por Vettore ${ }^{6}$, é preciso que mecanismos que assegurem a qualidade da avaliação por pares sejam desenvolvidos, para que:

a qualidade do processo editorial seja sustentada pela legitimidade e credibilidade da avaliação por pares e que, em especial na área da Saúde Coletiva, as novas evidências advindas das pesquisas publicadas em nossos periódicos possam contribuir para aperfeiçoar os serviços de saúde e melhorar a qualidade de vida da população.

Apesar de a má prática na pesquisa e na publicação de trabalhos na área biomédica não ser um tema exclusivamente recente, é veemente necessário que as transgressões à ética científica, desde plágio, falsificação de dados, até fraudes completas, passando por publicação de material redundante sem novidade para a ciência, sejam, definitivamente, abolidas. Em tempos em que a avaliação do desempenho acadêmico é realizada, com um devido peso, pela análise da quantidade de publicações em periódicos científicos ${ }^{7}$, é preciso que o processo editorial seja conduzido de forma ética, incluindo a avaliação pelos pares dos manuscritos submetidos à publicação.

Por fim, agradeço ao Prof. Dr. Ricardo Peres do Souto a oportunidade de contribuir junto aos ABSC e pelo espaço dedicado a esse editorial. A abertura de espaços para discussões como esta, em periódicos de reconhecida qualidade no âmbito nacional e internacional, certamente implica no aumento de esperanças relativas ao desenvolvimento de uma ciência honesta, justa e ética, na qual a má prática científica, envolvendo as diferentes instâncias no processo editorial, e a responsabilização e punição de pesquisadores desonestos seja uma realidade nos meios de comunicação científica nacionais. No Brasil, infelizmente, o controle social da ciência ainda inexiste e é muito pouco discutido.

Desejo a todos uma ótima leitura do presente volume dos ABCS e convidamos autores/pesquisadores a submeterem seus trabalhos a esse periódico.

\section{Quadro 1: Tipos de conduta antiética e falsificação em publicações científicas e técnicas}

\begin{tabular}{|l}
\hline Por parte dos autores \\
Apresentar dados ou artefatos que não existem; \\
Apresentar documentos ou objetos forjados; \\
Falsificar dados reais ou provas ou dados deliberadamente distorcidos; \\
Usar ideias ou textos de outras pessoas sem atribuir-lhes a autoria (plágio), inclusive deliberada violação de direitos do autor (copyright); \\
Falsificar a autoria, omitindo um autor; \\
Falsificar a autoria, incluindo autor que não colaborou para o trabalho; \\
Falsificar o status da publicação. \\
Por parte dos revisores de artigos \\
Falsificar fatos ou emitir parecer mentiroso; \\
Retardar a apresentação do parecer, sem motivos razoáveis, a fim de obter vantagens pessoais; \\
Roubar ideias ou textos de um manuscrito que esteja examinando. \\
Por parte dos editores de periódicos, assistentes e equipes editoriais \\
Forjar ou fabricar fraudulentamente um parecer; \\
Mentir para um autor a respeito do processo de emissão de pareceres; \\
Roubar ideias ou texto de um manuscrito submetido a exame.
\end{tabular}

\section{Referências}

1. Rennie D, Flanagin A, Godlee F, Groves T. Seventh International Congress on Peer Review and Biomedical Publication, September 2013: call for research. JAMA. 2012;307(7):726-7.

2. Pessanha C. Critérios editoriais de avaliação científica: notas para discussão. Ci Inf. 1998;27(2):226-9.

3. Pizzani L, da-Silva RC, Hossne WS. Análise bibliométrica dos 40 anos da produção científica em Bioética no Brasil e no mundo. Rev Bioethikos. 2010;4(4):453-60.

4. Lafollette MC. Stealing into print: fraud, plagiarism and misconduct in scientific publishing. Berkeley: University of California Press; 1992.

5. Tavares-Neto J, Azevêdo ES. Destaques éticos nos periódicos nacionais das áreas médicas. Rev Assoc Med Bras. 2009;55(4):40-1.

6. Vettore MV. 0 processo editorial de avaliação por pares em revistas na área da saúde. Cad Saude Publica. 2009;25(11):2306-07.

7. Malafaia G, Rodrigues ASL. Confecção de um artigo científico relacionado à área da saúde: problemas e desafios a serem superados. Arq Bras Ciên Saúde. 2010;35(2):86-8. 